\title{
pARIS-htt: an optimised expression platform to study huntingtin reveals functional domains required for vesicular trafficking
}

\author{
Raúl Pardo ${ }^{+1,2,3}$, Maria Molina-Calavita ${ }^{\dagger 1,2,3}$, Ghislaine Poizat1,2,3, Guy Keryer 1,2,3, Sandrine Humbert1,2,3 and \\ Frédéric Saudou*1,2,3
}

\begin{abstract}
Background: Huntingtin (htt) is a multi-domain protein of $350 \mathrm{kDa}$ that is mutated in Huntington's disease (HD) but whose function is yet to be fully understood. This absence of information is due in part to the difficulty of manipulating large DNA fragments by using conventional molecular cloning techniques. Consequently, few studies have addressed the cellular function(s) of full-length htt and its dysfunction(s) associated with the disease.

Results: We describe a flexible synthetic vector encoding full-length htt called pARIS-htt (Adaptable, RNAi Insensitive $\&$ Synthetic). It includes synthetic cDNA coding for full-length human htt modified so that: 1 ) it is improved for codon usage, 2) it is insensitive to four different siRNAs allowing gene replacement studies, 3) it contains unique restriction sites (URSs) dispersed throughout the entire sequence without modifying the translated amino acid sequence, 4) it contains multiple cloning sites at the N and C-ter ends and 5) it is Gateway compatible. These modifications facilitate mutagenesis, tagging and cloning into diverse expression plasmids. Htt regulates dynein/dynactin-dependent trafficking of vesicles, such as brain-derived neurotrophic factor (BDNF)-containing vesicles, and of organelles, including reforming and maintenance of the Golgi near the cell centre. We used tests of these trafficking functions to validate various pARIS-htt constructs. We demonstrated, after silencing of endogenous htt, that full-length htt expressed from pARIS-htt rescues Golgi apparatus reformation following reversible microtubule disruption. A mutant form of htt that contains a 100Q expansion and a htt form devoid of either HAP1 or dynein interaction domains are both unable to rescue loss of endogenous htt. These mutants have also an impaired capacity to promote BDNF vesicular trafficking in neuronal cells.

Conclusion: We report the validation of a synthetic gene encoding full-length htt protein that will facilitate analyses of its structure/function. This may help provide relevant information about the cellular dysfunctions operating during the disease. As proof of principle, we show that either polyQ expansion or deletion of key interacting domains within fulllength htt protein impairs its function in transport indicating that HD mutation induces defects on intrinsic properties of the protein and further demonstrating the importance of studying htt in its full-length context.
\end{abstract}

\section{Background}

Huntingtin (htt) is a protein of $350 \mathrm{kDa}$ that when mutated causes Huntington's disease (HD). HD is a devastating inherited neurodegenerative disorder characterized by the selective dysfunction and death of particular neurons in the brain $[1,2]$. The causative mutation is an abnormally expanded CAG tract in the 5 'coding region of

\footnotetext{
* Correspondence: Frederic.Saudou@curie.fr

1 Institut Curie, F-91405 Orsay, France

+ Contributed equally

Full list of author information is available at the end of the article
}

the htt gene that is translated into a long polyglutamine (polyQ) stretch in the N-terminal part of the protein. HD occurs when there are more than the threshold of 36 glutamines. The mechanisms leading to disease are not fully understood but involve both the gain of new toxic functions and the loss of normal htt function(s) [1-3]. For example, loss of htt function in the transcription of brainderived neurotrophic factor (BDNF) and in its microtubule (MT)-dependent transport participates in HD pathogenesis $[4,5]$. We and others have contributed to the 
identification and characterization of postranslational modifications within htt that regulate the function(s) of both the wild-type protein and the toxicity induced by the mutant version. These findings demonstrate the importance of the protein context. The first identified modification of htt was its phosphorylation at serine 421 (S421). Htt S421 is phosphorylated by Akt and the Serum and Glucocorticoid-induced kinase (SGK) and is dephosphorylated by calcineurin [6-9]. Phosphorylation at S421 is abnormally low in disease [9-11]. Dephosphorylation of S421 is associated with reduced htt function in the MTdependent transport of BDNF in neurons and may contribute to the selective neurodegeneration in cases of HD $[12,13]$. Htt is cleaved by several proteases, including caspase 6 which may play a crucial role and modify disease progression [14]. PolyQ-htt susceptibility to cleavage is regulated by phosphorylation of serine 434 by Cdk5 [15] and of serine 536 by an unidentified kinase [16]. Also, the specific acetylation of mutant htt at lysine 444 leads to its selective degradation by autophagy, thereby reducing toxicity [17]. Subcellular trafficking of htt and its association with lipid membranes can be modified by palmitoylation of cysteine 214 [18]. Palmitoylation-resistant mutants accelerate formation of inclusions and neuronal toxicity. Mass spectrometry experiments have identified additional phosphorylation sites in the central and carboxyterminal parts of the protein [16] which may be involved in additional mechanisms regulating its cellular functions. Sequence analysis revealed at least 36 HEAT (huntingtin, elongation factor 3, PR65/A subunit of protein phosphatase $2 \mathbf{A}$ and $\mathrm{m}$ Tor) repeats dispersed throughout the protein $[19,20]$. The presence of these domains and the predicted structure of htt are consistent with a cellular role as a scaffold protein [21,22]. In agreement, more than one hundred interactors have been reported in yeast-two-hybrid screens using various htt fragments as baits $[23,24]$. The protein sequence, including the central and carboxy-terminal part of the protein, has been very highly conserved throughout evolution. These various observations all indicate the importance of the full-length protein context when addressing htt functional studies. They have also led to the emerging notion that understanding normal htt function is essential if we are going to understand the pathogenic and regulatory events that occur during disease progression in HD patients.

Various cellular and molecular biology techniques can be used to study the function(s) of a particular protein and its dysfunction(s) when mutated. Many of these techniques require cloning the gene of interest into appropriate vector(s) for subsequent characterization. This step can be extremely laborious and time consuming especially when dealing with large proteins, like htt, and may constitute a difficult technical obstacle for extensive functional and genetic analyses. Because of this problem, and despite the very large number of publications concerning HD since the cloning of the htt gene in 1993, most studies have used only short $\mathrm{N}$-terminal fragments of the htt protein and focused on the gain of toxic function elicited by the polyQ stretch. Indeed, expression of short N-terminal fragments (containing the pathogenic expansion), for example the 89 amino acid fragment corresponding to the exon 1, are sufficient to generate a neurological phenotype in mice and to induce the death of various cell types [25]. Although these models reproduce some pathological features observed in HD patients, exon 1 encodes less than $3 \%$ of the full-length htt protein; consequently, such studies do not necessarily provide a complete image of the function(s) of the protein and the dysfunction(s) operating during HD. In particular, the translational product of exon 1 does not contain important sites of post-translational modifications, notably S421, L444 and $\mathrm{C} 214$, that critically regulate mutant htt toxicity. In addition, events such as caspase 6 proteolysis of the fulllength protein are bypassed in such models. Also, functional studies on the role of htt in MT-dependent transport have shown that wild-type full-length htt, but not short amino-terminal fragments such as that encoded by exon 1, stimulates the transport of BDNF-containing vesicles [5]. These observations make clear the need for appropriate tools to study wild-type and pathogenic htt in its full-length protein context.

We report the construction and validation of a complete synthetic htt gene with wild-type and mutant versions. We demonstrate that the wild-type htt encoded by this gene has a positive effect in regulating the trafficking of vesicles and organelles; the pathogenic mutant htt does not. We exploited the versatility of this synthetic htt gene to generate internal deletions and demonstrate that the regions interacting with $\mathrm{HAP} 1$ and dynein are required to mediate htt function in cellular trafficking. Thus, this fully synthetic construct will be useful for investigations of htt function and the pathogenic mechanisms underlying HD.

\section{Results}

pARIS-htt, a synthetic cDNA encoding a tagged full-length version of human huntingtin

We designed a synthetic cDNA covering the entire sequence of human htt as part of a modular and versatile plasmid expression platform to study the function(s) of the protein. This system includes all the benefits of the Gateway system from Invitrogen. We named this platform pARIS-htt (Adaptable, RNAi Insensitive \&Synthetic). The sequence of human htt (GenBank access NM 002111) was optimized for eukaryotic codon usage. We also exploited the degenerate nature of the genetic code to eliminate various restriction sites from the sequence and introduce others, resulting in a synthetic 
DNA sequence with unique restriction sites every 1-1.5 $\mathrm{kbp}$ on average without modifying the amino acid sequence encoded (GenBank access NP 002102)(Figure 1A). The overall construction strategy required first the synthesis and cloning of eight fragments separately in the vector pUC19. The full-length version of the htt gene was then generated by assembling the eight fragments (Figure 1A). In the resulting construct, the entire sequence can be divided into eight different fragments, each single fragment being flanked by unique restriction sites.

The multi-cassette nature of pARIS-htt is advantageous. Any desired mutation of the full-length context can be generated in two steps. The first step is the introduction of the desired mutation into the corresponding 1 to $1.5 \mathrm{kbp}$ fragment in pUC19. The second step is to reintroduce the mutated fragment into the full-length htt cDNA by conventional restriction enzyme digestion and ligation. PolyQ expansion in the htt protein causes HD, so we produced pARIS-htt versions with and without a sequence encoding an abnormal polyQ stretch. We generated a pARIS-htt version encoding a pathogenic polyQ expansion of $100 \mathrm{Q}$ by introducing alternate CAG-CAA repeats, because the alternating codons are genetically more stable [26]. The NotI site upstream from the sequence encoding the first $\mathrm{N}$-ter 17 amino acids and the SacI site downstream from that encoding the poly-proline stretch (amino acid position 92) allow the introduction of a sequence encoding a synthetic $\mathrm{N}$-terminal fragment with CAG repeats of any desired size by simple digestion with NotI/SacI followed by insertion of a compatible cassette coding for the polyQ sequence of desired length. We generated two different cassettes coding for 23 and 100Q.

To facilitate functional studies, the pARIS-htt constructs were designed to allow production of various fusion proteins: tagging of the amino terminus of the encoded protein with a $6 \times$ histidine-tag to allow protein purification on $\mathrm{Ni}^{2+}$ columns, and fusion to the mCherry protein; the $\mathrm{C}$-terminus was tagged with haemaglutinin (HA) that can be used for immunoprecipitation or immunohistochemistry, and a tetracysteine tag (TC-Tag) that allows the fusion protein to be specifically recognized in living cells by biarsenic labelling reagents such as FlAsH$\mathrm{EDT}_{2}$ and $\mathrm{ReAsH}-\mathrm{EDT}_{2}[27,28]$. The sequences encoding the tags can be easily removed by using the unique NotI and EcoRI restriction sites and multicloning sites (MCS) at the two extremities (Figure 1A; sequences and vector maps are provided in additional files 1 and 2). Another important feature of pARIS-htt is its full compatibility with the Gateway technology, which allows recombination-based cloning and all its benefits in terms of time and simplicity. This property is provided by the inclusion of the specific recombination sites attB1 and attB2 flanking the htt coding sequence. First, the htt coding wild- type and mutant sequences were transferred to a general donor plasmid (pDONR201, Invitrogen) to generate Entry vectors in which pARIS-htt is flanked by attL sequences (BP clonase reaction). These Entry vectors are referred as follows: pARIS-htt-N[His-mCherry]Q23C[HA-TC] and pARIS-htt-N[His-mCherry]Q100-C[HATC]. pARIS-htt sequences can then be transferred to the desired destination vector though a second recombination (LR clonase reaction) to generate an expression clone. Numerous commercially available destination vectors can be used for straightforward expression of synthetic human htt protein in diverse biological systems (transient expression in mammalian cells, baculovirusmediated infection of insect cells, lentiviral-mediated delivery to neural cells or expression in Drosophila melanogaster).

\section{pARIS-htt drives expression of full-length huntingtin and is insensitive to siRNAs targeting the endogenous protein}

To validate pARIS-htt constructs, we first generated a pcDNA-based (pcDNA3.2-DEST, Invitrogen) expression vector to drive pARIS-htt expression in mammalian cells. The constructs pARIS-httpcDNA3.2-N[His-mCherry]Q23C[HA-TC] (pARIS-mCherry-httQ23) and pARIShttpcDNA3.2-N[His-mCherry]Q100-C[HA-TC] (pARISmCherry-httQ100) were used to transfect HEK cells and protein expression was analyzed by immunoblotting with various htt-specific antibodies recognizing different epitopes within the protein, including htt-4C8 whose epitope maps to positions 443-457 of the amino acid sequence and the htt- $2 \mathrm{C} 1$ antibody raised against the carboxy-terminal region (2788-2990) [29,30] (Figure 1A). These two antibodies gave strong signals for the synthetic htt constructs with migration shifts due to the presence of the tags for pARIS-mCherry-httQ23 and that of the expanded polyQ stretch for pARIS-mCherry-httQ100 (Figure 1B). pARIS-mCherry-httQ100 but not Q23 was selectively recognized by antibody $1 \mathrm{C} 2$ that binds specifically to pathogenic polyQ expansions [31]. The synthetic constructs containing a C-terminal HA tag were also efficiently recognized by anti-HA antibodies. We next investigated whether expression of pARIS-htt in transfected Cos7 cells could be detected by direct immunofluorescence due to its $\mathrm{N}$-terminal mCherry fluorescent tag. The fluorescent signals corresponding to pARIS-mCherryhttQ23 and pARIS-mCherry-httQ100 were mainly cytosolic and colocalized with htt-4C8 staining (Figure 1C). This localization is in agreement with previous studies [29].

The pARIS constructs are suitable for use in gene replacement strategies. Indeed, the sequence was modified to make it insensitive to various siRNAs that efficiently silence human, rat or mouse htt (see Methods section for the list of siRNAs that can be used and addi- 

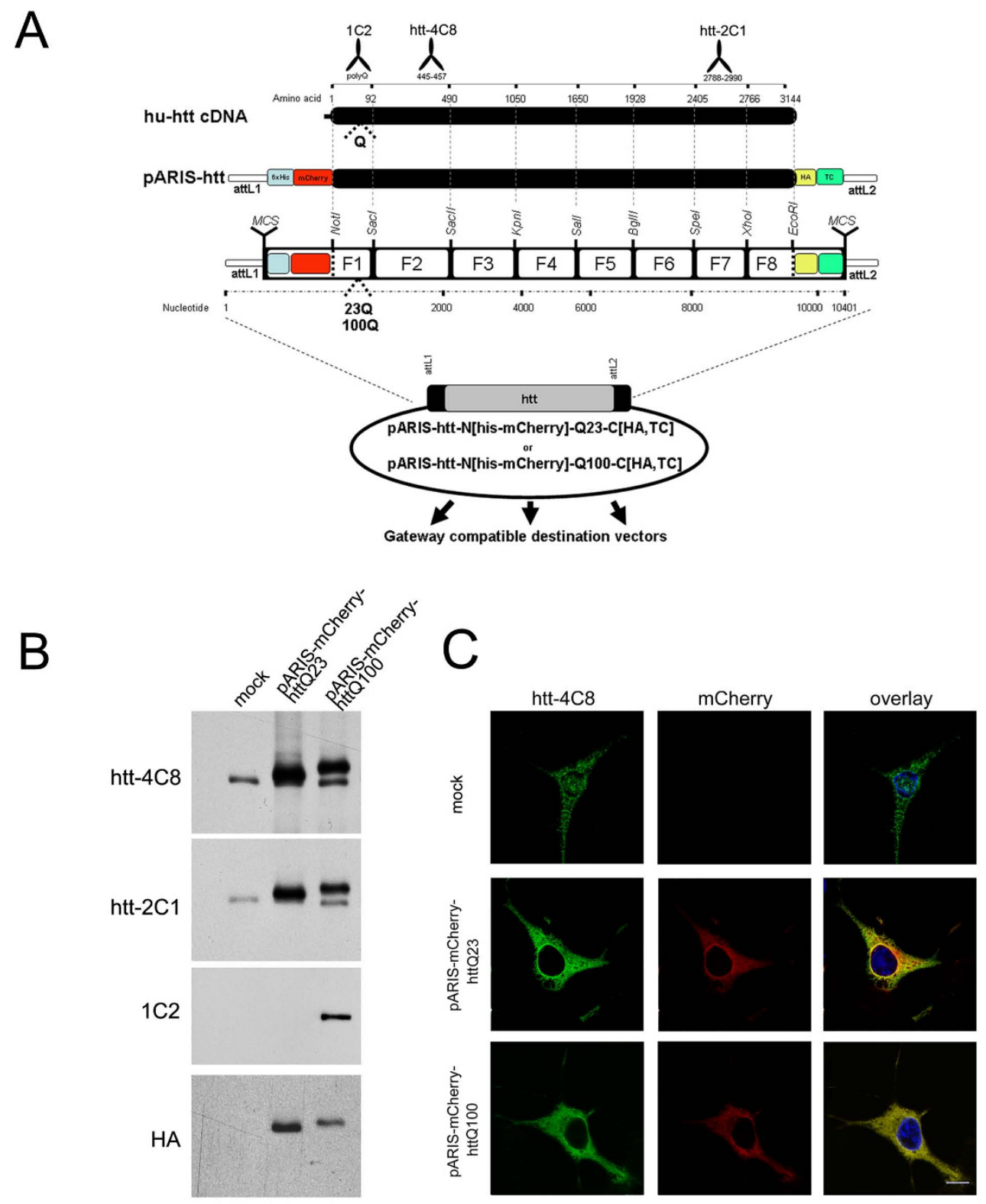

Figure 1 pARIS-htt an Adaptable, RNAi Insensitive \& Synthetic construct encoding human huntingtin. A) Schematic representation of pARIShtt. The entire coding sequence is divided into 8 different fragments, each fragment being flanked by unique restriction sites every 1-1.5 kbp and cloned independently into a modified pUC19 backbone. A multi-cassette full-length htt plasmid (pARIS-htt) was generated by assembly of these 8 individual fragments. PARIS-htt construct was tagged with $6 \times$ His followed by a mCherry on the amino terminus. The carboxy-terminal part contains HA and tetracysteine (TC) tags. The synthetic construct is fully compatible with the Gateway technology thanks to the introduction of flanking attL sites. (B) pARIS-htt triggers the expression of full-length htt in HEK cells. Cells mock transfected and transfected with pARIS-mCherry-httQ23 or pARISmCherry-httQ100 were analyzed by western blot using antibodies raised against different regions of htt: the amino-terminal part (htt-4C8), the carboxy-terminal part (htt-2C1) or the pathogenic polyQ stretch (1C2). The exact epitopes for these antibodies are illustrated in (A). Expression of the different constructs was detected using a high affinity anti-HA antibody. (C) Confocal images of Cos 7 mock transfected cells and cells transiently transfected with pARIS-mCherry-httQ23 or pARIS-mCherry-httQ100 constructs. Expression of pARIS-htt is detected as a cytosolic mCherry fluorescent signal which codistributes with htt-4C8 antibody staining. Scale bar $10 \mu \mathrm{m}$. 
tional file 1 for their positions within htt sequence). We previously reported a similar strategy for replacing endogenous htt with exogenous $\mathrm{N}$-ter amino acid fragments of htt $[9,13]$. Here, we significantly improved the pertinence of this approach, because pARIS-htt allows the re-expression of full-length htt versions in various cellular contexts (human, mouse or rat cells) in which the endogenous htt is silenced. As a proof of principle, we specifically silenced endogenous htt in HeLa cells using a human specific siRNA, siRNA-hu-htt-585, which is particularly effective for knocking-down htt expression in cells of human origin (data not shown). HeLa cells were transfected with control RNA (scRNA) or siRNA-hu-htt585 using lipofectamine, transfected $24 \mathrm{~h}$ later with pARIS-htt constructs, and then incubated for an additional $24 \mathrm{~h}$. Expression of both endogenous and exogenous htt was analyzed by Western blotting (Figure 2A). Production of endogenous htt was completely abolished by the siRNA without affecting pARIS-mCherry-httQ23/ Q100, whose expression was detected using an anti-HA antibody. Thus, pARIS-htt is fully insensitive to siRNAs targeting htt and therefore can be used for replacement strategy experiments in cells.

\section{pARIS-htt can substitute endogenous huntingtin in a Golgi reassembly assay}

We exploited this RNAi insensitivity to develop a cellular test and to validate pARIS-htt as a functional htt protein. $\mathrm{Htt}$ is found in the Golgi apparatus (GA) [32-34]. In our hands, a significant fraction of pARIS-mCherry-httQ23 was similarly localized in discrete sites in the GA (data not shown). Knock-down of htt in cells results in the disruption of GA structure, leading to the suggestion that htt plays an active role in the maintenance of the GA structure near the cell centre [34]. Studies in which microtubules (MTs) were depolymerized or molecular motors were inactivated indicate that MTs and minus enddirected motors are also required to ensure the structural integrity and the perinuclear localization of the GA [3540]. The requirement for htt in the organisation and maintenance of the Golgi is linked to the interaction between htt and components of the dynein/dynactin complex [34]. We therefore set up a cellular test to assess htt function in the transport of Golgi-derived vesicles. We used HeLa cells stably expressing GFP-mannosidase II, a key enzyme of N-linked glycan processing often used as a medial Golgi marker [41]. As expected, silencing of htt was associated with the disruption of the GA structure as shown by the dispersion of Ctr433, a marker of the cis/median Golgi [42](Figure 2B). Most cells depleted of endogenous htt displayed spread GA, which was in many cases fully vesicular instead of being organized into compact perinuclear stacks as observed in most control (scRNA-treated) cells (Figure 2B). We next investigated the role of htt in MT-dependent assembly of the GA (Figure $2 \mathrm{C}-2 \mathrm{E})$. To do so, we treated the cells with nocodazole (NZ, $4 \mu \mathrm{M}, 120 \mathrm{~min}$ ) to allow complete depolymerization of the MT network (Figure $2 \mathrm{C}$, upper panel) and dispersion of the GA into numerous ministacks (Figure 2E, upper row) that localize at the exit sites of the endoplasmic reticulum [43]. GA integrity was then analyzed 120 min after NZ washout (Figure 2E, lower row). In scRNAtreated cells the Golgi structure became centrally reorganized again, after NZ washout, concomitant with the reformation of the MT network (Figure 2C, lower panel). In most if not all htt-silenced cells, the Golgi remained dispersed $120 \mathrm{~min}$ after NZ washout (Figure 2E, lower row) despite the MT network being completely reconstituted (not shown).

We next tested whether exogenous expression of pARIS-htt could complement the loss of endogenous htt for MT-dependent assembly of the GA. Expression of endogenous htt was knocked-down by treatment with siRNA-htt. Then, pARIS-mCherry-httQ23, insensitive to the siRNA-htt used, was expressed and cells were treated with NZ for 120 min (Figure 3A). We assessed the reassembly of the GA 120 min after NZ washout. A significant fraction of siRNA-htt-treated cells expressing pARIS-mCherry-httQ23 could efficiently reorganize the GA into stacks in the perinuclear region (Figure 3B). Thus, pARIS-mCherry-httQ23 can substitute for endogenous htt to reassemble the GA into tight stacks.

The role of wild-type htt in GA maintenance has been previously studied [34]. However, it is not known whether pathogenic htt has altered functions in the reassembly of Golgi-derived membranes. We therefore used the same approach but with expression of pARIS-mCherryhttQ100 in cells depleted of endogenous htt. After NZ washout, the highly dispersed GA was unable to reassociate completely into a well-defined perinuclear structure (Figure 3B). Next we developed a system to quantify GA reassembly in this experimental model. We determined the mean volume of Golgi particles before $(t=0)$ and 120 min after NZ washout $(t=120$, figure $3 C)$. NZ treatment induced the complete disintegration of the GA into numerous ministacks with a mean volume of $0.28 \pm 0.04$ $\mu^{3}$. In control cells (scRNA), 120 min after NZ washout, the mean volume per particle increased approximately 15 fold $\left(4.13 \pm 0.77 \mu \mathrm{m}^{3}, \mathrm{p}<0.0001\right)$. In cells depleted of endogenous htt, Golgi-derived vesicles completely failed to cluster and fuse (siRNA-htt, $\mathrm{t}=0$ vs $\mathrm{t}=120 ; \mathrm{p}=0.634$, NS). Expression of pARIS-mCherry-httQ23 in httdepleted cells completely restored the assembly of Golgi ministacks $\left(3.763 \pm 0.71 \mu \mathrm{m}^{3}, \mathrm{t}=0\right.$ vs $\left.\mathrm{t}=120, \mathrm{p}<0.0001\right)$ and their transport to perinuclear regions. By contrast, pARIS-mCherry-httQ100 was unable to promote reassembly of the GA ( $p=0.432, \mathrm{NS})$. This experiment indicates that synthetic-Q23 htt restores MT-dependent 


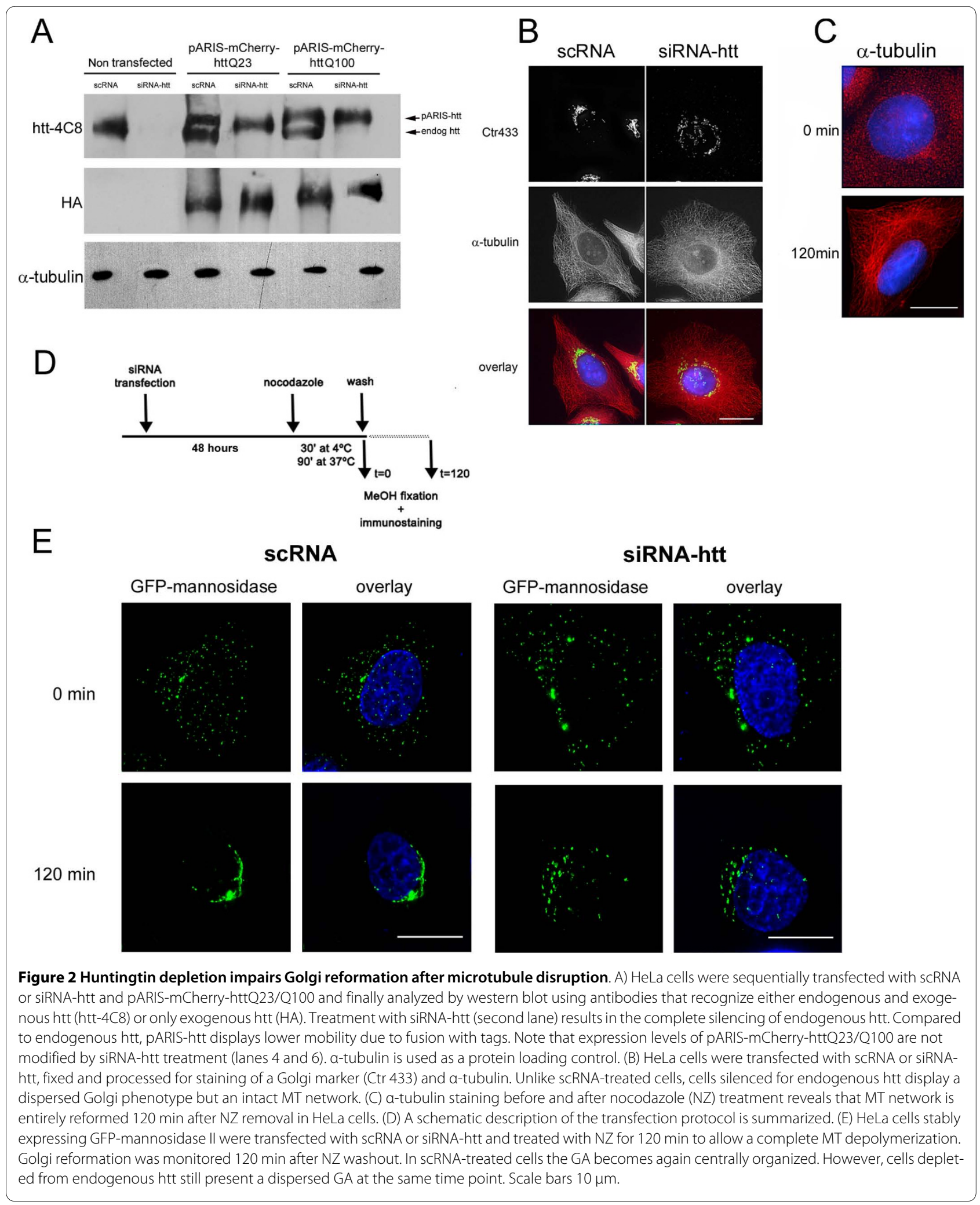



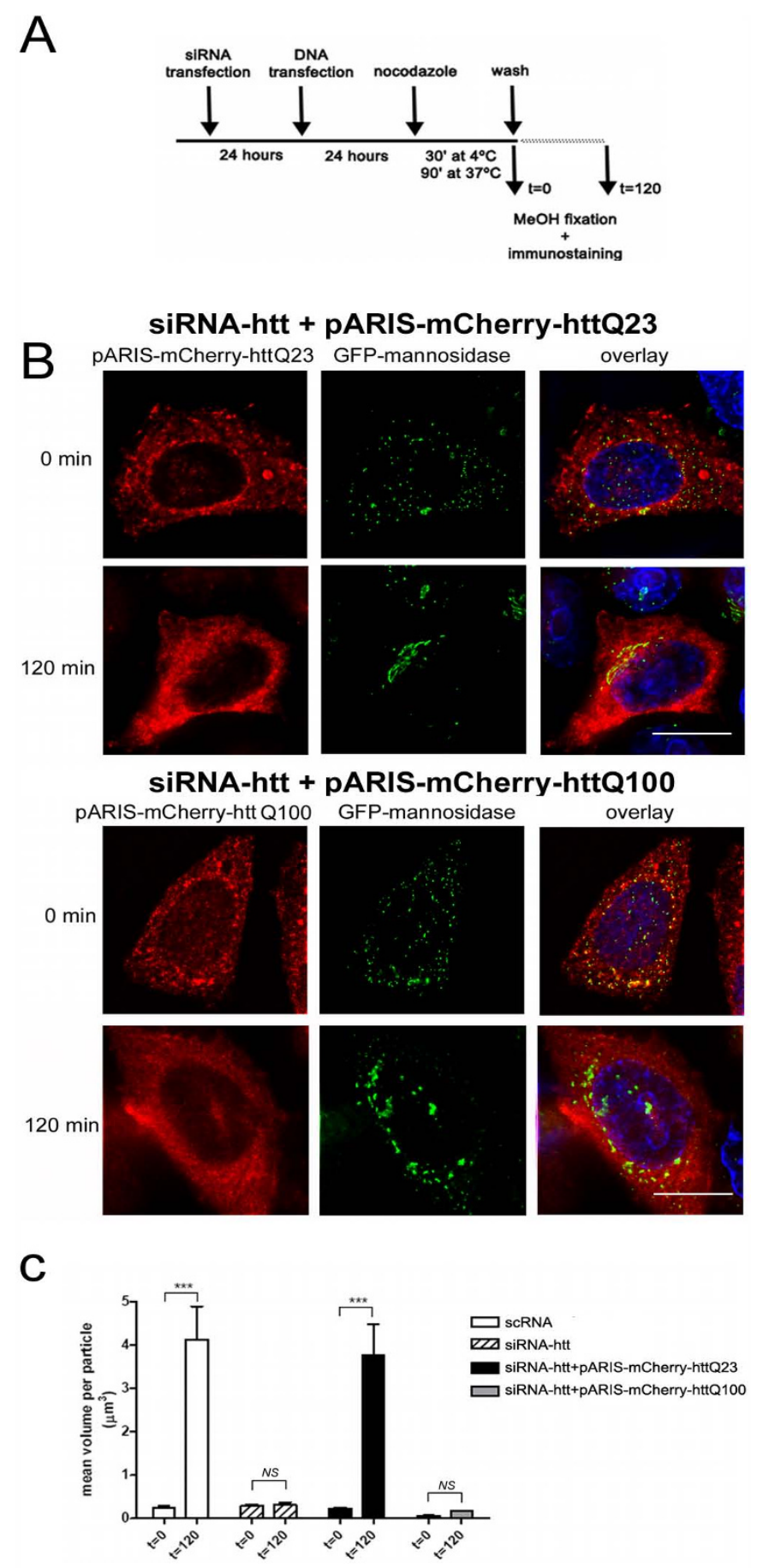

Figure 3 pARIS-mCherry-httQ23 but not pARIS-mCherry-httQ100 restores Golgi reassembly after endogenous huntingtin depletion. A) Gene replacement experiments and Golgi reformation assays were performed adding back pARIS-mCherry-httQ23/Q100 in cells depleted from endogenous htt following the protocol indicated in the scheme. (B) Representative images of cells expressing pARIS-mCherry-httQ23 (upper pannel) or pARIS-mCherry-httQ100 (lower panel) at $\mathrm{t}=0$ and $\mathrm{t}=120$ after NZ washout. While cells expressing pARIS-mCherry-httQ23 completely reassemble the GA into tight stacks, cells expressing pARIS-mCherry-httQ100 display scattered Golgi fragments that are unable to reassemble in the perinuclear region. (C) Quantification of the GA reassembly is presented as an analysis of mean Golgi particle volume $\left(\mu \mathrm{m}^{3}\right)$ before and after NZ washout for different treatments. Results were obtained from 3 independent experiments in which 280 cells were analyzed. One way ANOVA followed by Fisher's Post-hoc test: ${ }^{* *} \mathrm{p}<0.0001$; NS non significant. All comparisons are $t=0$ vs $t=120$; scRNA: $0.283 \pm 0.044$ vs $4.126 \pm 0.771$; siRNA-htt $0.073 \pm 0.008$ vs $0.158 \pm$ 0.06; siRNA-htt + pARIS-mCherry-httQ23: $0.222 \pm 0.035$ vs $3.763 \pm 0.712$; siRNA-htt + pARIS-mCherry-httQ100: $0.062 \pm 0.006$ vs $0.171 \pm 0.013$. 
assembly of the GA in cells with no endogenous htt. More importantly, it shows that the pathogenic polyQ expansion impairs the htt function allowing Golgi reassembly.

\section{The dynein/dynactin-interacting domains of huntingtin are required for Golgi apparatus reassembly}

Our findings indicate that physiological organization of the GA requires wild-type htt and that this function of htt is impaired by polyQ expansion. This is in agreement with previous studies linking htt function to the dynein/ dynactin-dependent transport of organelles along MTs $[5,12,13,34]$. Htt interacts with the dynein intermediate chain (DIC) via a minimal interaction region mapping to amino acid positions 536-698 of htt [34] and with dynactin via HAP1 [44-46] with a minimal interacting region corresponding to amino acids 171-230 of htt [47]. We have previously shown that the htt/HAP1 complex is necessary for vesicle transport along MTs. Depletion of HAP1 through siRNA treatment impairs BDNF transport along MTs in neuronal cells [5]. We have also shown that expression of wild-type exon 1 of htt that lacks the HAP1 binding region, does not stimulate BDNF transport in neuronal cells; by contrast, a 480 amino acid N-ter fragment can stimulate such transport. Although informative, these experiments have limited relevance because, due to the difficulty of manipulating full-length htt, they are based on the expression of truncated forms with most of the protein being deleted. Therefore, it is unknown whether these domains are required within a full-length htt context as mediators of htt regulatory function in the dynein/dynactin complex.

To investigate the htt-dynein interaction, we generated a version of pARIS-htt from which part of the dyneininteracting region was deleted (pARIS-mCherry-httQ23$\Delta$ dyn). We used immunoprecipitation experiments to test the ability of this deletion mutant to bind dynein. We used an antibody raised against htt (htt-4C8) to pulldown both endogenous and synthetic htt from non transfected cells and from cells expressing pARIS-mCherryhttQ23 (Figure 4A, upper panel). Under these conditions, dynein co-immunoprecipitated with htt provided the cells express either endogenous htt or pARIS-mCherryhttQ23. Similarly, both endogenous and exogenous htt were co-immunoprecipitated with dynein as shown by the presence of a doublet band (Figure 4A, lower panel). This doublet band was observed in cells transfected with pARIS-mCherry-httQ23 but was absent from non transfected cells and from cells expressing pARIS-mCherryhttQ23 but silenced for endogenous htt. Silencing experiments and re-expression of htt siRNA-insensitive constructs were then used to assess the interaction between dynein and the various exogenous htt constructs. In particular, we tested the interaction between dynein and fulllength htt lacking the internal dynein-binding domain.
Anti-htt antibodies could not immunoprecipitate dynein from pARIS-mCherry-httQ23- $\Delta$ dyn expressing cells silenced for endogenous htt (Figure 4B, upper panel). Conversely, although endogenous htt was efficiently immunoprecipitated by an anti-dynein antibody, pARISmCherry-httQ23- $\Delta$ dyn was not (Figure 4B, lower panel). This strongly indicates that pARIS-mCherry-httQ23$\Delta$ dyn lacking the dynein-interaction domain does not bind dynein.

Next we studied the effect of the expression of pARISmCherry-httQ23- $\Delta$ dyn on GA reassembly. Unlike in cells expressing pARIS-mCherry-httQ23 (Figure 3B, upper panel), GA stacks remained dispersed in cells expressing pARIS-mCherry-httQ23- $\Delta$ dyn (Figure $4 C$ ). We then quantified GA reassembly (as in Figure $3 \mathrm{C}$ ) and found that the GA clearly failed to reassemble following NZ washout (Figure 4D). This demonstrates a strong defect in the fusion of Golgi-derived mini-stacks in the presence of pARIS-mCherry-httQ23- $\Delta$ dyn (siRNA-htt + pARISmCherry-httQ23- $\Delta$ dyn, $\mathrm{t}=0$ vs $\mathrm{t}=120 ; \mathrm{p}=0.4883$, NS). In summary, we show that the htt-dynein interaction is required for the positive effect of htt on GA fusion and transport.

Another mechanism by which htt may regulate the dynein-dynactin complex involves the interaction between htt and huntingtin-associated protein 1 (HAP1), the first htt-interacting protein described. The association between these two proteins is enhanced when htt contains a pathogenic polyQ stretch [44]. HAP1 interacts with dynactin $[45,46]$ and plays a key role in MT-dependent transport of organelles in concert with htt $[5,12,48]$. Since the minimal interacting region of htt for HAP1 has been mapped to amino acid positions 171-230 of htt [47], we generated a version of pARIS-httQ23 deleted for this domain referred to hereafter as pARIS-mCherry-httQ23$\triangle$ HAP1.

We analyzed whether the pARIS-mCherry-httQ23$\triangle$ HAP1 mutant could bind to HAP1. We co-transfected HEK cells with GFP-tagged HAP1 and either pARISmCherry-httQ23 or pARIS-mCherry-httQ23- $\triangle$ HAP1. Co-immunoprecipitation experiments demonstrated that the htt construct not containing the 170-268 amino acid region did not bind to HAP1 (Figure 5A) and therefore that this region is necessary for interaction between fulllength htt and HAP1. We next tested the effect of this deletion on Golgi reassembly. Unlike cells expressing pARIS-mCherry-httQ23, cells expressing pARISmCherry-httQ23- $\triangle$ HAP1 could not reorganize the GA even 120 min after NZ washout (Figure 5B), despite complete reorganization of the MT network (not shown). Quantification of the mean volume of Golgi-derived particles (Figure 5C) confirmed the substantial defect in the fusion of GA ministacks in cells expressing pARISmCherry-httQ23- $\triangle$ HAP1 $(t=0$ vs $t=120, p=0.63$, NS). 

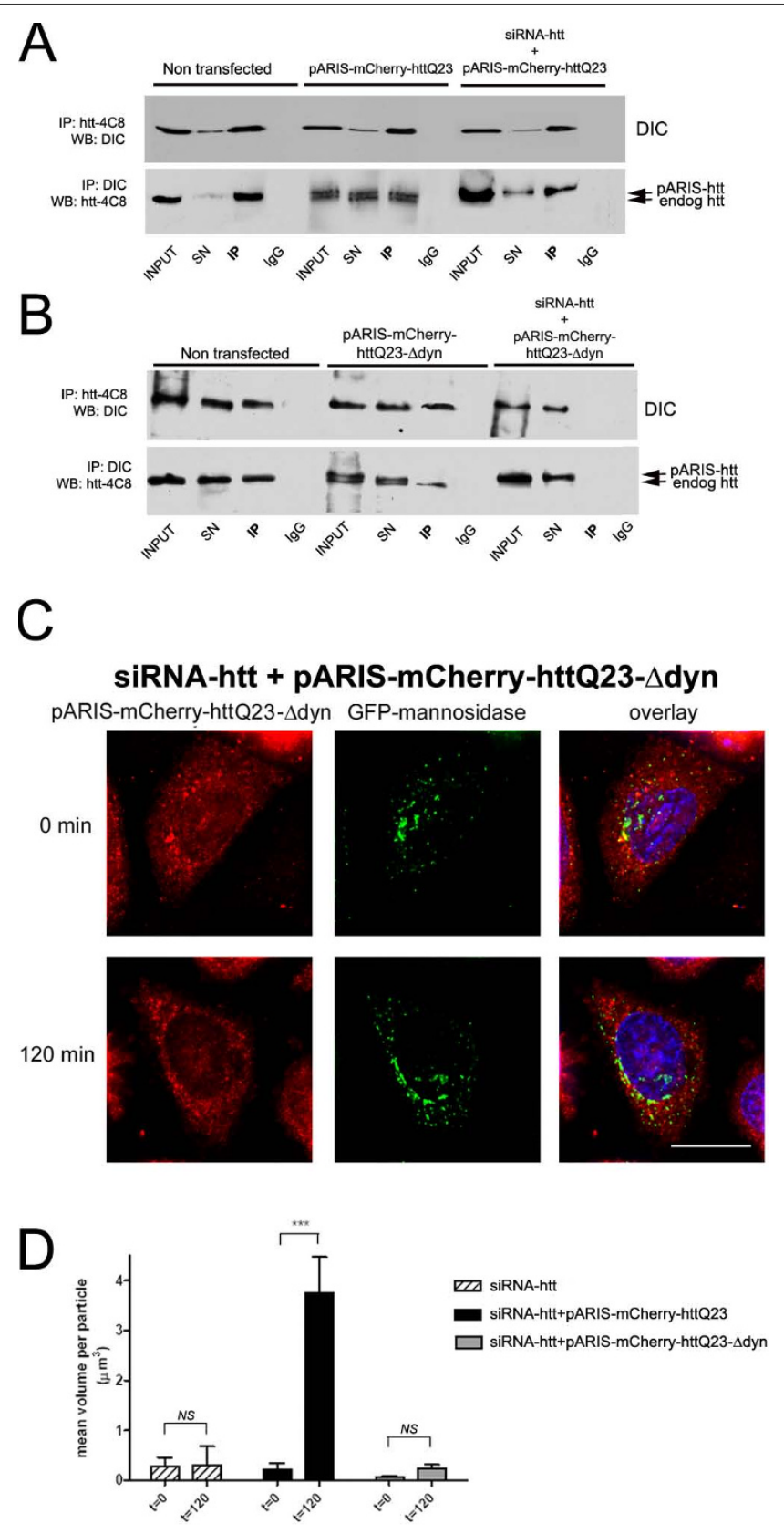

Figure $4 \mathrm{Htt}$ requires dynein interacting domain to facilitate the transport of Golgi-derived vesicles. A) HEK cells were treated with scRNA or siRNA-htt prior transfection with pARIS-mCherry-httQ23. Cellular lysates were immunoprecipitated using htt-4C8 or anti-dynein (DIC) antibodies and immunocomplexes were subjected to SDS-PAGE to detect either htt or dynein. Dynein co-precipitates with htt when htt-4C8 antibody is used to pulldown endogenous and exogenous htt (Upper panel). Conversely, immunoprecipitation of dynein (lower panel) pulls down both endogenous and exogenous htt (indicated by arrows, lower mobility band corresponding to pARIS-mCherry-httQ23). The same amount of mouse or rabbit lgG's were used as internal immunoprecipitation controls. SN stands for supernatant; IP denotes immunoprecipitation. B) A deletion mutant lacking the minimal dynein interaction domain, denoted as pARIS-mCherry-httQ23- $\Delta$ dyn, is unable to bind to endogenous dynein (lane 11). (C) Golgi reassembly was monitored in HeLa cells stably expressing GFP-mannosidase II, silenced for endogenous htt and expressing pARIS-mCherry-httQ23- $\triangle$ dyn as the only cellular source of htt. Most of the cells expressing pARIS-mCherry-httQ23- $\triangle$ dyn failed to reassemble the GA after NZ washout, suggesting that httdynein interaction is required to transport retrogradely Golgi-derived vesicles. Scale bar $10 \mu \mathrm{m}$. (D) Quantification of the Golgi dispersion as the mean volume per Golgi particle $\left(\mu^{3}\right)$ before and after after NZ washout for the different treatments. Results were obtained from 3 independent experiments in which 192 cells were scored. One way ANOVA followed by Fisher's Post-hoc test: ${ }^{* * *} p<0.0001$; NS non significant. All comparisons $t=0$ vs $\mathrm{t}=120$; siRNA-htt $0.073 \pm 0.008$ vs $0.158 \pm 0.06$; siRNA-htt + pARIS-mCherry-httQ23: $0.222 \pm 0.035$ vs $3.763 \pm 0.712$; siRNA-htt + pARIS-mCherry-httQ23$\triangle$ dyn: $0.073 \pm 0.010$ vs $0.244 \pm 0.072$ 
A

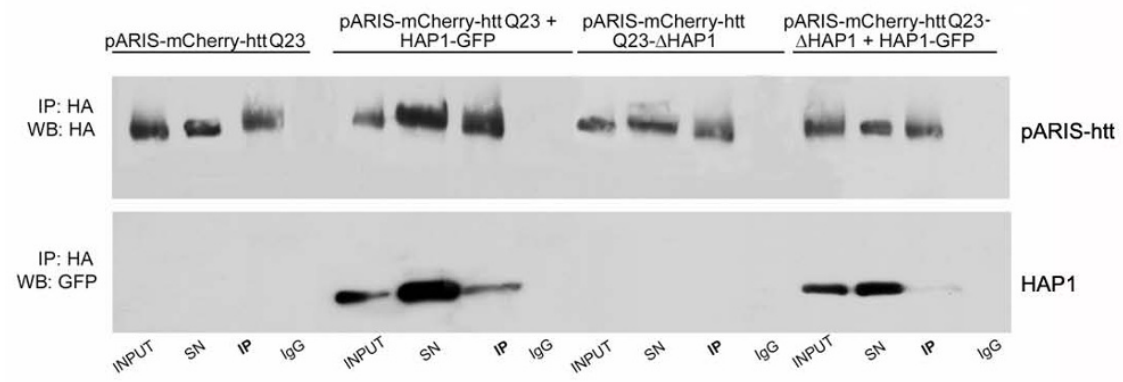

B

\section{siRNA-htt + pARIS-mCherry-httQ23- $\triangle$ HAP1}

pARIS-mCherry-httQ23-AHAP1 GFP-mannosidase
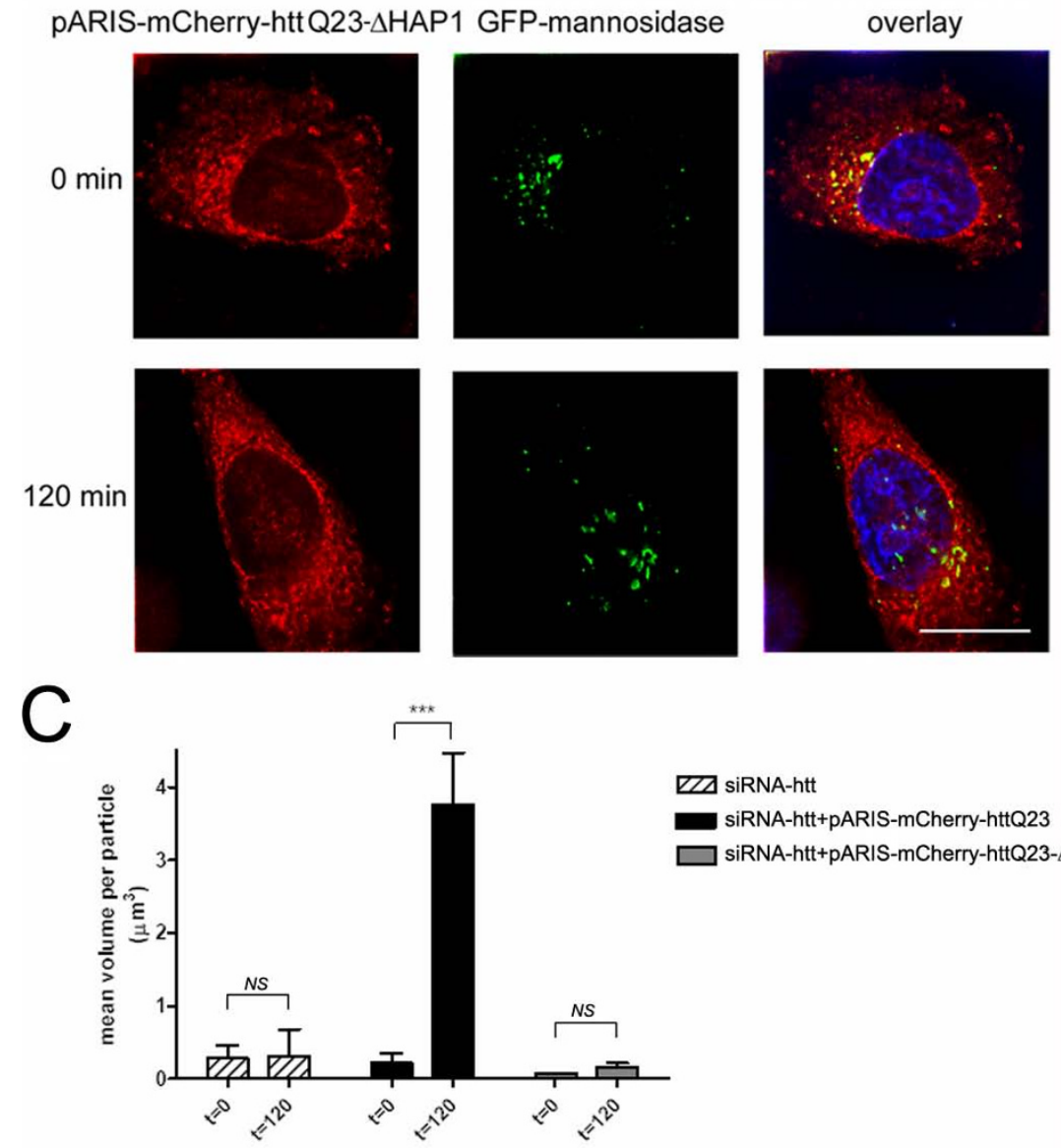

Figure $5 \mathrm{Htt}$ requires HAP1 interacting domain to facilitate the transport of Golgi-derived vesicles. A) HEK cells were transfected with pARISmCherry-httQ23 or a deletion mutant for the minimal HAP1 interaction domain (denoted as pARIS-mCherry-httQ23- $\triangle$ HAP1) in the absence or presence of HAP1-GFP. Exogenous htt was immunoprecipitated (IP) from cell lysates using a HA antibody and immunocomplexes were analyzed for the presence of HAP1-GFP. Immunoprecipitations with mouse lgGs were used as a specificity control. (B) Golgi reformation assays were done in HeLa cells stably expressing GFP-mannosidase II as described previously. Representative image of a pARIS-mCherry-httQ23- $\triangle H A P 1$ expressing cell failing to reconstitute the GA after NZ washout. Scale bar $10 \mu \mathrm{m}$. (C) Quantification of the Golgi dispersion as the mean volume per Golgi particle ( $\mu \mathrm{m}^{3}$ ) before and after NZ washout for the different treatments. Results were obtained from 3 independent experiments in which 190 cells were scored. One way ANOVA followed by Fisher's Post Hoc test: ${ }^{* * *} \mathrm{p}<0.0001$. NS, non significant. All comparisons $t=0$ vs $t=120$; siRNA-htt $0.073 \pm 0.008$ vs $0.158 \pm 0.06$; siRNA-htt + pARIS-mCherry-httQ23: $0.222 \pm 0.035$ vs $3.763 \pm 0.712 ;$ siRNA-htt + pARIS-mCherry-httQ23- $\triangle$ HAP1: $0.073 \pm 0.080$ vs $0.159 \pm 0.060$. 
Our results show the importance of HAP1 in the MTdependent transport of GA-derived vesicles.

Together, our results further extend the role of htt in the maintenance of GA. Indeed, we demonstrate that the capacity of htt to regulate the retrograde transport of dispersed Golgi vesicles to form highly organized stacks around the perinuclear region requires a functional interaction between htt and both dynein and HAP1.

\section{pARIS-httQ23 but not pARIS-httQ100, pARIS-httQ23- $\Delta$ dyn} nor pARIS-httQ23- $\triangle$ HAP1 promotes BDNF transport in neuronal cells

MT-dependent transport of vesicles, such as BDNF, is regulated by the association between htt and the dynein/ dynactin complex $[5,12,13,34]$. Wild-type htt has a positive effect on vesicular dynamics whereas this function is lost in HD $[5,12,13,34]$. Therefore, the regulatory functions of htt in vesicular trafficking can be evaluated by comparing neurons that express wild-type htt or mutant $h t t$. We previously described the effect of wild-type and pathogenic versions of htt on the dynamics of vesicles that contain eGFP or mCherry-tagged BDNF $[5,12,13]$. These approaches are sensitive enough to be used to evaluate drugs that restore MT-dependent transport that is altered during $\mathrm{HD}[5,9,12,13,49]$.

We analyzed the dynamics of BDNF-eGFP-containing vesicles in mouse neuronal cells using fast $3 \mathrm{D}$ videomicroscopy followed by deconvolution. Videomicroscopy was performed one day after electroporation of cells with BDNF-eGFP alone or BDNF-eGFP with pARISmCherry-httQ23 and pARIS-mCherry-httQ100, in conditions in which no apparent toxicity was observed. The combination of mCherry-htt and BDNF-eGFP facilitated identification of cells to be recorded during videoexperiments. pARIS-mCherry-httQ23 showed a similar transport function as wild-type htt, significantly increasing the mean velocity of BDNF vesicles $(1.132 \pm 0.030 \mu \mathrm{m} / \mathrm{s} \mathrm{com}$ pared to the control value: $0.733 \pm 0.044 \mu \mathrm{m} / \mathrm{s} ;{ }^{* * * * *} \mathrm{p}<$ 0.0001 , figure $6 \mathrm{~A})$. The presence of pARIS-mCherryhttQ100 did not stimulate BDNF transport $(0.810 \pm 0.056$ $\mu \mathrm{m} / \mathrm{s})$. In cells expressing pARIS-mCherry-httQ100, the pausing time, corresponding to the percentage of time the vesicles spent without moving, was significantly longer than in controls (from $3.09 \pm 0.49 \%$ in control cells to $5.83 \pm 1.03 \%$, figure $6 \mathrm{~B}$ ). The pausing time in cells expressing pARIS-httQ23 was not significantly different from control values $(3.00 \pm 0.38 \%)$.

$\mathrm{Htt}$ function in MT-dependent transport of BDNF also involves dynein/dynactin and HAP1. We therefore investigated BDNF dynamics in neuronal cells expressing pARIS-mCherry-httQ23- $\Delta$ dyn or pARIS-mCherryhttQ23- $\triangle$ HAP1. Relative to control values, pARISmCherry-httQ23 increased BDNF trafficking in cells, whereas each pARIS-mCherry-httQ23- $\Delta$ dyn and pARIS-

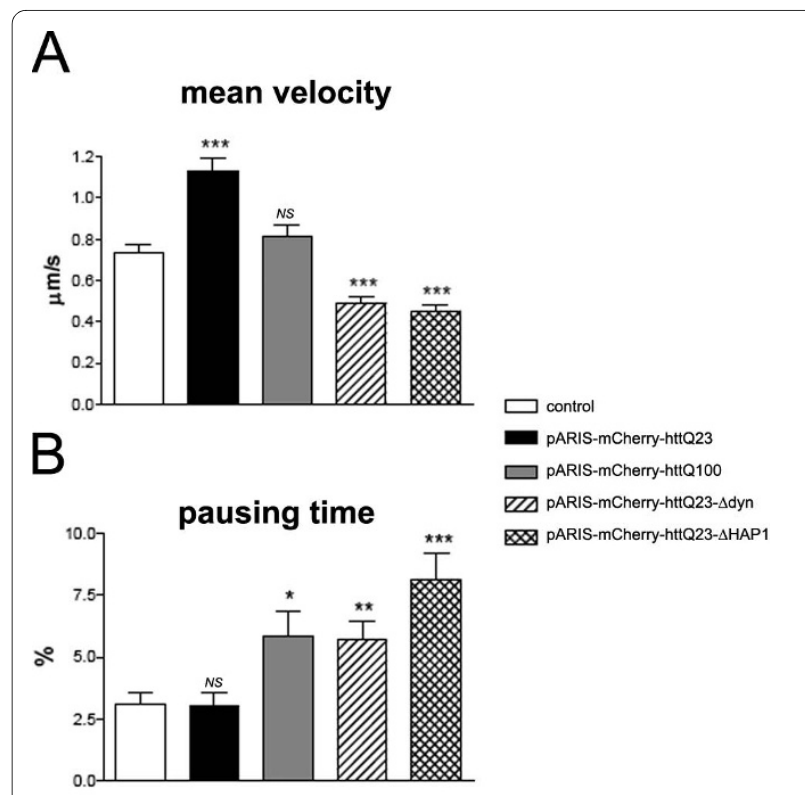

Figure 6 pARIS-mCherry-httQ23 facilitates BDNF transport through interaction with dynein and HAP1. A) Fast 3D videomicroscopy was performed to analyze the dynamics of BDNF-eGFP-containing vesicles in mouse neuronal cells expressing BDNF-eGFP alone or cotransfected with pARIS-mCherry-httQ23/Q100 or dynein/HAP1 deletion mutants. Overexpression of pARIS-mCherry-httQ23 recapitulates the transport function of wild-type htt and significantly increases the mean velocity of BDNF-containing vesicles compared to controls values (BDNF transfection alone). Nor the polyQ version neither pARIShtt deletion mutants are able to stimulate the transport of BDNF containing vesicles. The pausing time of moving vesicles is quantified in (B). Mean overall velocity is indicated as $\mu \mathrm{m} / \mathrm{sec}$. Data were obtained from three independent experiments (control: 4805 tracks from 39 cells; pARIS-mCherry-httQ23: 1970 tracks from 20 cells; pARIS-mCherry-httQ100: 1670 tracks from 18 cells; pARIS-mCherry-httQ23- $\triangle$ dyn: 4603 tracks from 25 cells; pARIS-mCherry-httQ23- $\triangle$ HAP1: 4029 tracks from 20 cells). Fisher's analysis: ${ }^{*} P<0.05$; ${ }^{* *} \mathrm{P}<0.01$, NS, non significant.

mCherry-httQ23- $\triangle$ HAP1 mutants reduced the mean velocity (Figure 6A). Similarly, we also observed a significantly longer pausing time of BDNF-containing vesicles in cells expressing pARIS-mCherry-httQ23- $\Delta$ dyn or $\triangle$ HAP1 mutants than in cells expressing pARISmCherry-httQ23 (Figure 6B). These findings further extend the functional role of full-length htt as a key regulator of MT-dependent transport of organelles in cells. Furthermore, we clearly show that in mammalian neuronal cells, in a physiological full-length protein context, this positive function is mediated by two independent domains of htt protein: the HAP1- and dynein-interacting regions.

\section{Discussion}

There is currently substantial evidence consistent with $h t t$ being a scaffold protein required for diverse cellular functions, including various intracellular trafficking pro- 
cesses. Unravelling htt functions in different tissues and how these functions are spatially and temporally tuned to the needs of the cell (via a plethora of post-translational modifications) is extremely complex. In particular, it requires working in the context of the full-length protein. Due in part to htt being a very large protein, this approach has been technically difficult and most experiments addressing htt function, toxicity or post-translational modifications have used short $\mathrm{N}$-terminal fragments of htt; many studies have been based on exon1 that corresponds to less than $3 \%$ of the protein. Here we present a flexible platform to render working with the full-length protein much more straightforward. Our pARIS-htt platform can be used for the construction of tagged and mutant versions of htt in a full-length context. We successfully produced tagged versions of wild-type and mutant htt in various cell lines and generated mutants unable to interact with known protein partners: dynein and HAP1 (pARIS-mCherry-httQ23- $\Delta$ dyn and pARIS-mCherry-httQ23- $\Delta$ HAP1). In the absence of htt, the GA is disrupted, indicating that htt is required to maintain GA organization around the centrosome $[33,50]$. Indeed, a fraction of htt localizes to the GA and may serve to regulate the post-Golgi trafficking of proteins [32]. We used this property to establish reconstitution experiments to validate our pARIS-htt constructs. Our experimental model is based on the complete silencing of endogenous htt and the expression of various synthetic htt constructs in HeLa cells stably expressing a fluorescent GA-resident protein (GFP-mannosidase II). We used NZ treatment and monitored subsequent reassembly of the GA. In cells expressing pARIS-mCherryhttQ23, the GA was completely reassembled $120 \mathrm{~min}$ after NZ washout. By contrast, cells expressing any of the three mutant pARIS-htt constructs (pARIS-mCherryhttQ100, pARIS-mCherry-httQ23- $\Delta$ dyn or pARISmCherry-httQ23- $\triangle$ HAP1) failed to reassemble their GA: dispersed ministacks were observed, instead of tightly organized GA around the cell centre, suggesting a defect in the retrograde transport of Golgi-derived vesicles. Quantification of the mean volume of Golgi-derived particles revealed a profound defect in the fusion events in cells expressing any of the mutants, a defect which was not observed in cells expressing pARIS-mCherry-httQ23. These data are in agreement with previous results linking htt function to the maintenance of the GA via dynein [50]. We also validated pARIS-htt constructs for their function in the MT-dependent transport of BDNF-containing vesicles: pARIS-mCherry-httQ23 made a positive contribution to transport whereas this function was lost in neuronal cells expressing pARIS-mCherry-httQ100. Interestingly, BDNF transport, as assessed by measuring BDNF vesicle velocities, was disrupted more strongly by pARIS-mCherry-httQ23- $\Delta$ dyn and pARIS-mCherry-
httQ23- $\triangle$ HAP1 than by pARIS-mCherry-httQ100. These experiments demonstrate the requirement of the dynein (633-672) and HAP1 (168-270) interacting regions for htt function in the context of the full-length protein. Furthermore, they suggest that htt regulates vesicular trafficking via distinct but functionally important domains. These results support the notion of htt as a scaffold protein linking vesicles and MTs and promoting the association and regulation of components of the molecular motor machinery, including HAP1 and the motors dynein or kinesin. In agreement with this view, phosphorylation of htt at S421 regulates the recruitment of kinesin-1 to the motor complexes thereby coordinating the directionality of vesicular transport in cells [12]. Moreover, our results strongly suggest that pathogenic polyQ expansions may influence the protein's conformation and its association with motor complexes.

The study of htt function(s) in health and disease is complex, because the protein is widely distributed, but the pathological mutant disables only a small subset of neurons and does so only after many years. Numerous questions concerning the cellular functions of wild-type $\mathrm{htt}$ remain unanswered. The role of htt in the regulation of vesicular trafficking is one of its best-described functions $[5,12,13,34]$ and is certainly not limited to its association with dynein or HAP1. Indeed, the contribution of $\mathrm{htt}$ to different membrane trafficking events involves other protein partners, such as HIP-1 [51], HAP40 [52], Rab8/optineurin [32,53] or Rab11 [54]. Determination of the true contribution of the reported vesicular trafficking defects to the pathology of HD will certainly require more comprehensive studies. Any such studies would be strengthened by working with the full-length protein, so pARIS-htt constitutes a valuable expression platform for future investigations.

Finally, the combination of yeast-two-hybrid techniques with biochemical approaches led to the identification of more than 100 non redundant htt-interactors. These factors can be classified into different functional groups, including proteins involved in cytoskeletal organization, signal transduction, synaptic transmission, proteolysis and regulation of transcription or translation $[23,24,55]$. It is important to validate these interacting proteins as bona fide genetic modifiers, so that they can then be used to provide insight into the normal function of htt in neuronal and non-neuronal cells, and into the molecular pathogenesis of HD. Here again, pARIS-htt may be a valuable tool for use with other biological approaches for exploring these issues.

\section{Conclusions}

We present a comprehensive set of vectors designed for mutation/tagging and expression of full-length huntingtin. We hope this vector platform will be of value to the 
scientific community and facilitate functional and genetic studies of htt in the near future.

\section{Methods}

Statistical analyses

InfoStat software version 2009 (InfoStat Group, FCA, Cordoba National University, Argentina) was used for the analysis of variance and followed by a post hoc LSD Fisher's test. Data are expressed as mean +/- S.E.M. "P < $0.05 ; * \mathrm{P}<0.01 ; * * * \mathrm{P}<0.001$.

\section{Constructs and siRNA}

The plasmid encoding BDNF-eGFP was previously described $[5,56]$. BDNF-eGFP shows cellular localization, processing, and secretion properties indistinguishable from those of endogenous BDNF. The plasmid encoding for the huntingtin-associated protein 1 (HAP1) tagged with GFP was a gift of XJ Li (Emory University, Atlanta, USA). The siRNA targeting human huntingtin (siHtthu585, Eurogentec, Seraing, Belgium) corresponds to the coding region 279-298 of human htt mRNA (NCBI ref. seq. NM_002111). The control RNA (scRNA, ATCGAGCTACCACGAACGCTT, Eurogentec) has a unique sequence which does not match to any sequence in the genome of interest.

\section{Construction of pARIS-htt}

pARIS-htt was engineered based on the cDNA of fulllengh human htt using OptGene (Ocimum Biosolutions, Hyderabad, India) gene optimizing tool. Gene synthesis was performed by assembly of oligonucleotides using proprietary in-house protocols of BaseClear BV (Leiden, Netherlands). The original sequence was designed with a polyglutamine stretch of 23 glutamines. Glutamine repeats were encoded by alternate CAG/CAA codons to provide more genetic stability. The first base on the start translation codon is considered position number 1 .

The pARIS-htt sequence has been rendered insensitive to different siRNAs commonly used in our laboratory: siHtt-1.1 AAGAACTTTCAGCTACCAA (human specific, position 275-293); siHtt-hu585 AACTTTCAGCTACCAAGAAAG (human specific, position 279-298); siHtt-6: AAGCTTTGATGGATTCTAA (human specific, position 474-492); siHtt-13: GCAGCTTGTCCAGGTTTAT (human, rat and mouse specific, position 10621080). siHtt-hu585 was used in this study because it is particularly effective to knock-down endogenous htt expression in cells of human origin (referred as siRNA-htt throughout the text).

The full-length engineered pARIS-htt construct was entirely sequenced and inserted into HindIII/BamHI sites of a pUC19 variant (Baseclear BV) for amplification. The pARIS-htt sequence contains flanking attL1 and attL2 sites to allow recombination into pDON201 donor vector
(BP clonase reaction, Invitrogen, Carlsbad, USA). A second recombination with pcDNA3.2-DEST (Invitrogen) using LR clonase was necessary to generate a pcDNA3based destination vector. Recombinations were done in a $10 \mu \mathrm{l}$ final volume following instructions provided by the manufacturer. Amplification of the constructs was done in TOP10 or DH5 $\alpha$ E. coli strains (Invitrogen). A DNA fragment of htt containing a polyQ stretch of 100 glutamines was synthesized using alternative protocols by Geneart AG (Regensburg, Germany) and inserted into NotI/SacI sites of pARIS-htt to replace the 23Q stretch. Vector maps are available in additional file 1.

We use the following nomenclature to describe the first step constructs in the Entry vector: pARIS-htt-N[HismCherry $]$ Q23-C[HA-TC] and pARIS-htt-N[HismCherry]Q100-C[HA-TC]. These constructs were transposed to pcDNA3.2 to generate pARIS-httpcDNA3.2 $\mathrm{N}$ [His-mCherry]Q23-C[HA-TC] (pARIS-mCherryhttQ23) and pARIS-httpcDNA3.2-N[His-mCherry]Q100C[HA-TC] (pARIS-mCherry-httQ100).

To generate the htt construct deleted for the dyneininteracting domain, the deletion was first generated within the F3 fragment (pUC19-F3 $\Delta 633-672$ ), transposed to Entry-based pARIS-htt by insertion of SacII/KpnI (fragment 3) generating pARIS-htt-N[HismCherry]Q23- $\Delta 633-672-\mathrm{C}[\mathrm{HA}-\mathrm{TC}]$ and next transposed to pcDNA3.2 to generate pARIS-httpcDNA3.2-N[HismCherry]Q23- $\Delta 633-672-C[H A-T C]$ hereafter denoted pARIS-mCherry-httQ23- $\Delta$ dyn. To generate the htt construct deleted for the HAP1 binding domain, the deletion was first generated within the F2 fragment (pUC19F2 $\Delta 170-268$ ), transposed to Entry-based pARIS-htt by insertion of SacI/SacII (fragment 2) generating pARIShtt-N[His-mCherry]Q23- $\Delta 170-268-\mathrm{C}[\mathrm{HA}-\mathrm{TC}]$ and next transposed to pcDNA3.2 to generate pARIS-httpcDNA3.2_ $\mathrm{N}[$ His-mCherry]Q23- $\Delta$ 170-268-C[HA-TC] hereafter denoted pARIS-mCherry-httQ23- $\Delta$ HAP1. Requests for constructs may be sent to the following e-mail address: paris-htt.constructs@curie.fr.

\section{Cell Culture}

$\mathrm{HEK}$ and Cos7 cells were grown at $37^{\circ} \mathrm{C}$ in $5 \% \mathrm{CO} 2$ in Dulbeco's modified Eagle's medium (DMEM) supplemented with $10 \%$ bovine calf serum, $1 \% \mathrm{~L}$-glutamine and antibiotics $(50$ units $/ \mathrm{ml}$ penicillin and $50 \mu \mathrm{g} / \mathrm{ml}$ streptomycin). HeLa cells stably expressing GFP-mannosidase II (gift of F. Perez, Institut Curie, Paris, France), were grown at $37^{\circ} \mathrm{C}$ in $5 \% \mathrm{CO}_{2}$ and cultured in DMEM supplemented with $10 \%$ bovine calf serum, $1 \%$ L-glutamine and $400 \mu \mathrm{g} /$ $\mathrm{ml}$ geneticin (Gibco, Carlsbad, USA). Mouse neuronal cells, ST $\mathrm{Hdh}^{+/+}$cells derived from immortalized striatal progenitor cells were grown as previously described [57]. 


\section{Cell Transfection}

For pARIS-htt expression analysis, HEK cells were transfected with pARIS-mCherry-httQ23, pARIS-mCherryhttQ100 or equivalent amount of empty vector, using the calcium phosphate method [58]. Western blot analysis was performed after 24-48 h.

For immunofluorescence experiments, Cos7 cells seeded in 12-well plates with $18 \mathrm{~mm}$ coverslips were transfected with pARIS-mCherry-httQ23, pARISmCherry-httQ100 or equivalent amount of empty vector using FuGENE reagent (Roche, Mannheim, Germany) according to the manufacturer's instructions. Immunostaining was done after $48 \mathrm{~h}$.

For gene replacement experiments, HeLa cells stably expressing GFP-mannosidase II were seeded in 12-well plates with $18 \mathrm{~mm}$ coverslips. Sequential transfection was performed as following: attached cells were first transfected using Lipofectamine 2000 (Invitrogen) with siRNA-htt or scRNA. After $24 \mathrm{~h}$, cells were transfected again with pARIS-mCherry-httQ23, pARIS-mCherryhttQ100, pARIS-mCherry-httQ23- $\Delta$ dyn or pARISmCherry-httQ23- $\triangle$ HAP1. Cells were processed for western blotting or immunostaining $24 \mathrm{~h}$ after. DNA, siRNA and Lipofectamine 2000 quantities were used according to the manufacturer's instructions.

To perform co-immunoprecipitation experiments, HEK cells were transfected using Lipofectamine 2000 with siRNA-htt as described above. After $24 \mathrm{~h}$ the cells were transfected with pARIS-mCherry-Htt constructs and/or HAP1-GFP using the calcium phosphate method. Immunoprecipitation assays were performed after $24 \mathrm{~h}$.

For videomicroscopy experiments mouse neuronal cells were electroporated with Kit L Nucleofector according to the supplier's manual (Amaxa, Köln, Germany). BDNFeGFP and pARIS-htt DNA or equivalent amount of empty vector were added to the electroporation mix. After electroporation, cells were seeded in 12 well plates with $18 \mathrm{~mm}$ coverslips.

\section{Nocodazole treatment}

Transfected HeLa GFP-mannosidase II cells were treated with $4 \mu \mathrm{M}$ nocodazole for $30 \mathrm{~min}$ at $4^{\circ} \mathrm{C}$ and $90 \mathrm{~min}$ at $37^{\circ} \mathrm{C}$ to allow a complete depolymerization of microtubules. Cells were washed twice with DMEM prior to methanol fixation $\left(2 \mathrm{~min}\right.$ at $\left.-20^{\circ} \mathrm{C}\right)$.

\section{Antibodies}

Anti-huntingtin antibodies used in this study htt-4C8, htt-2C1 and 1C2 were previously described [29,31], $\alpha-$ tubulin was from Sigma (St Louis, USA), high affinity anti-HA and anti-GFP were from Roche, anti-dynein intermediate chain (DIC) was from Chemicon (Billerica, USA), secondary IgG-HRP antibodies were from Jackson
ImmunoResearch (WestGrove, USA), the mouse monoclonal antibody against the cis/medial Golgi marker CTR433 was previously described [42]. Alexa Fluor secondary antibodies used in immunofluorescence experiments were from Invitrogen.

\section{Western Blot}

Transfected cells were harvested and lyzed in $50 \mathrm{mM}$ Tris- $\mathrm{HCl}, \mathrm{pH} 7.5$, containing $0.1 \%$ Triton $\mathrm{X}-100,2 \mathrm{mM}$ EDTA, 2 mM EGTA, $50 \mathrm{mM} \mathrm{NaF}, 10 \mathrm{mM} \beta$-glycerophosphate, $5 \mathrm{mM}$ sodium pyrophosphate, $1 \mathrm{mM}$ sodium orthovanadate, $0.1 \%(\mathrm{v} / \mathrm{v}) \quad \beta$-mercaptoethanol, $250 \mu \mathrm{M}$ PMSF, $10 \mathrm{mg} / \mathrm{ml}$ aprotinin and leupeptin. Cell lysates were centrifuged at 20,000 $\mathrm{g}$ for $10 \mathrm{~min}$ at $4^{\circ} \mathrm{C}$. Equal amounts of protein were subjected to SDS-PAGE on $6 \%$ polyacrylamide gels and transferred to nitrocellulose membranes (Whatman, Dassel, Germany). Blocked membranes (5\% milk in TBS-0.1\% Tween-20) were incubated with mouse anti-huntingtin antibodies (htt-4C8, htt-2C1), mouse anti-polyQ expansion (1C2), rat anti$\mathrm{HA}$, mouse anti-GFP, mouse anti-DIC or mouse anti- $\alpha-$ tubulin antibodies and washed three times with TBS$0.1 \%$ Tween-20 for $10 \mathrm{~min}$. Membranes were then labelled with secondary IgG-HRP antibodies raised against each corresponding primary antibody. After three washes, the membranes were incubated with SuperSignal West Pico Chemiluminescent Substrate (Pierce, Erembodegem, Belgium) according to the instructions of the supplier. Membranes were exposed to Amersham Hyperfilm $^{\mathrm{TM}}$ MP (GE Healthcare, Buckinghamshire, UK) films and developed.

\section{Immunoprecipitation}

Immunoprecipitations were performed as described [59] with minor modifications. Cell lysis and wash of the immunocomplexes were done in $50 \mathrm{mM}$ of Tris $1 \mathrm{M}$ (pH 8), $150 \mathrm{mM} \mathrm{NaCl}$ and 1\% of NP40 containing protease and phosphatase inhibitors. Briefly, transfected cells were harvested and lyzed on ice. Lysates were centrifuged at $16,000 \mathrm{~g}\left(15 \mathrm{~min}\right.$ at $\left.4^{\circ} \mathrm{C}\right)$ and precleared $\left(30 \mathrm{~min}\right.$ at $\left.4^{\circ} \mathrm{C}\right)$ using protein A-Sepharose beads (Sigma). Cleared lysates were incubated for 2-3 h at $4^{\circ} \mathrm{C}$ with protein A-Sepharose beads conjugated to mouse htt-4C8, mouse DIC or rat HA antibodies. Immunoprecipitates were washed three times and analyzed by Western blot as described.

\section{Immunofluorescence}

After methanol fixation cells were blocked for $1 \mathrm{~h}$ at RT with PBS-BSA 3\% and incubated with primary antibodies for $1 \mathrm{~h}$ prior staining with Alexa Fluor secondary antibodies. Nuclei were stained with DAPI (Roche). The mounting medium was $0.1 \mathrm{~g} / \mathrm{ml}$ Mowiol 4-88 (Calbiochem, Darmstadt, Germany) in $20 \%$ glycerol. 


\section{Image acquisition}

Images on fixed samples were acquired at RT with a Leica SP5 laser scanning confocal microscope equipped with a $63 \times$ oil-immersion objective or with a Leica DM RXA microscope with a PL APO oil $63 \times$ NA of 1.4 objective coupled to a piezzo and a Micromax RTE/CCD-1300-Y/ HS camera controlled by Metamorph software (Molecular Devices, Sunnyvale, CA). Z-stack step was of $0.2 \mu \mathrm{m}$. All stacks were treated by automatic batch deconvolution using the PSF of the optical system, Meinel algorithm with parameters set at 7 iterations, 0.7 sigma and 4 frequencies.

\section{Computer morphometric analysis of the Golgi apparatus} Images of fixed cells were acquired as described (see above, image aquisition). Only HeLa cells stably expressing GFP-mannosidase II and transfected with our pARIShtt constructs were analyzed. Once deconvolved, images were analyzed with Image software using 3D object counter plugin ([60]; available at http://imagejdocu.tudor.lu/doku.php?id=plugin:analy-

sis:3d object counter:start). The quantification was achieved tagging each identified object within the $\mathrm{z}$ stacks (around $30 \mathrm{z}$-stacks per image), treating each Golgi particle as an individual object. Statistics about each object were calculated, volume as: number of voxels of the object $\times \mathrm{x}$ calibration $\times \mathrm{y}$ calibration $\times \mathrm{z}$ calibration. The overall measurements were obtained from 3 independent experiments and analyzed to determine the mean volume per particle for each condition.

\section{Videomicroscopy}

Mouse neuronal transfected cells were grown on glass coverslips and mounted in a Ludin's chamber. The microscope and the chamber were kept at $33^{\circ} \mathrm{C}$. Live videomicroscopy was carried out using a Leica DM IRBE microscope and a PL APO oil $100 \times$ objective with a numerical aperture of 1.40-0.70, coupled to a piezo device (PI) and recorded with Photometrics CoolSNAP HQ2 camera (Roper Scientific, Trenton, NJ) controlled by Metamorph software. Images were collected in stream set at $2 \times 2$ binning with an exposure time of 50-150 ms (frequency of $2 \mathrm{~s}$ ) with a Z-step of $0.3 \mu \mathrm{m}$. Deconvolution was performed as described for fixed samples. All dynamic parameters of intracellular transport were obtained from three independent experiments with a total of about 1500-5000 measures from 18-39 independent cells. Dynamics were characterized by tracking positions of eGFP vesicles as a function of time with an especially developed plugin (available at http:// rsb.info.nih.gov/ij/plugins/track/track.html) for Image J.

\section{Additional material}

\begin{abstract}
Additional file 1 Sequences and maps of pARIS-htt constructs used in the study. The file includes vector maps, DNA sequences, protein translation and additional information for pARIS-mCherry-httQ23/Q100 plasmids in Entry vector. They were generated using Gene Construction Kit (Textco BioSoftware, West Lebanon, USA) and Serial Cloner 2.0 (available at http:// serialbasics.free.fr/Serial Cloner.html.) software.

Additional file $\mathbf{2}$ Sequence text files of pARIS-htt constructs used in the study. It includes sequences of pARIS-mCherry-httQ23/Q100 plasmids in Entry and pcDNA vectors.
\end{abstract}

\section{Abbreviations}

The abbreviations used are BDNF: brain-derived neurotrophic factor; GA: Golgi apparatus; HD: Huntington's disease; htt: huntingtin; IP: immunoprecipitation; MT: microtubule; NZ: nocodazole; polyQ: polyglutamine; RT: room temperature; WB: western blot.

\section{Competing interests}

The authors declare that they have no competing interests.

\section{Authors' contributions}

RP, MMC, GK, SH and FS designed the experiments. RP, MMC and GP performed the experiments. RP, MMC, SH and FS analyzed the data. RP, MMC, SH and FS wrote the paper. All authors read and approved the final manuscript.

\section{Acknowledgements}

We thank E van Rijn and BaseClear BV (Leiden, Netherlands) for discussions, help in the design and completion of the synthetic gene project. We acknowledge K Colombo, JR Pineda and D Zala for help in data analysis and all the members of the Saudou and Humbert's laboratories for helpful comments; FP Cordelières and the Institut Curie Imaging Facility for image acquisition and treatment; M Bornens, XJ Li and F Perez for providing materials and reagents. This work was supported by grants from Agence Nationale pour la Recherche (ANR-MRAR-018-01 and ANR-08-MNP-039 to FS), Fondation pour la Recherche Médicale (FRM) and Fondation BNP Paribas (FS). RP was supported by a Beatriu de Pinós fellowship from Generalitat de Catalunya (Spain) and MMC by Institut Curie Ph.D. fellowship. FS and SH are investigators from Institut National de la Santé et de la Recherche Médicale. SH is co-investigator at Assistance Publique-Hôpitaux de Paris.

\section{Author Details}

IInstitut Curie, F-91405 Orsay, France, ${ }^{2}$ Centre National de la Recherche Scientifique, Unité Mixte de Recherche 3306, F-91405 Orsay, France and 3Institut National de la Santé et de la Recherche Médicale, Unité U1005, F91405 Orsay, France

Received: 27 April 2010 Accepted: 1 June 2010

Published: 1 June 2010

\section{References}

1. Borrell-Pages M, Zala D, Humbert S, Saudou F: Huntington's disease: from huntingtin function and dysfunction to therapeutic strategies. Cell Mol Life Sci 2006, 63(22):2642-2660.

2. Li S, Li XJ: Multiple pathways contribute to the pathogenesis of Huntington disease. Mol Neurodegener 2006, 1(1):19.

3. Cattaneo E, Zuccato C, Tartari M: Normal huntingtin function: an alternative approach to Huntington's disease. Nat Rev Neurosci 2005, 6(12):919-930

4. Zuccato C, Ciammola A, Rigamonti D, Leavitt BR, Goffredo D, Conti L, MacDonald ME, Friedlander RM, Silani V, Hayden MR, Timmusk T, Sipione $\mathrm{S}$, Cattaneo E: Loss of huntingtin-mediated BDNF gene transcription in Huntington's disease. Science 2001, 293(5529):493-498.

5. Gauthier LR, Charrin BC, Borrell-Pages M, Dompierre JP, Rangone H, Cordelieres FP, De Mey J, MacDonald ME, Lessmann V, Humbert S, Saudou $\mathrm{F}$ : Huntingtin controls neurotrophic support and survival of neurons by enhancing BDNF vesicular transport along microtubules. Cell 2004, 118(1):127-138 
6. Humbert S, Bryson EA, Cordelieres FP, Connors NC, Datta SR, Finkbeiner S, Greenberg ME, Saudou F: The IGF-1/Akt pathway is neuroprotective in Huntington's disease and involves Huntingtin phosphorylation by Akt. Dev Cell 2002, 2(6):831-837.

7. Rangone H, Poizat G, Troncoso J, Ross CA, MacDonald ME, Saudou F, Humbert S: The serum- and glucocorticoid-induced kinase SGK inhibits mutant huntingtin-induced toxicity by phosphorylating serine 421 of huntingtin. Eur J Neurosci 2004, 19(2):273-279.

8. Pardo R, Colin E, Regulier E, Aebischer P, Deglon N, Humbert S, Saudou F: Inhibition of calcineurin by FK506 protects against polyglutaminehuntingtin toxicity through an increase of huntingtin phosphorylation at S421. J Neurosci 2006, 26(5):1635-1645.

9. Pineda JR, Pardo R, Zala D, Yu H, Humbert S, Saudou F: Genetic and pharmacological inhibition of calcineurin corrects the BDNF transport defect in Huntington's disease. Mol Brain 2009, 2(1):33.

10. Colin E, Regulier E, Perrin V, Durr A, Brice A, Aebischer P, Deglon N, Humbert S, Saudou F: Akt is altered in an animal model of Huntington's disease and in patients. Eur J Neurosci 2005, 21(6):1478-1488.

11. Warby SC, Chan EY, Metzler M, Gan L, Singaraja RR, Crocker SF, Robertson $H A$, Hayden MR: Huntingtin phosphorylation on serine 421 is significantly reduced in the striatum and by polyglutamine expansion in vivo. Hum Mol Genet 2005, 14(11):1569-1577.

12. Colin E, Zala D, Liot G, Rangone H, Borrell-Pages M, Li XJ, Saudou F, Humbert S: Huntingtin phosphorylation acts as a molecular switch for anterograde/retrograde transport in neurons. Embo J 2008, 27(15):2124-2134

13. Zala D, Colin E, Rangone H, Liot G, Humbert S, Saudou F: Phosphorylation of mutant huntingtin at $\mathrm{S} 421$ restores anterograde and retrograde transport in neurons. Hum Mol Genet 2008, 15; 17(24):3837-46.

14. Graham RK, Deng Y, Slow EJ, Haigh B, Bissada N, Lu G, Pearson J, Shehadeh J, Bertram L, Murphy Z, Warby SC, Doty CN, Roy S, Wellington CL, Leavitt BR, Raymond LA, Nicholson DW, Hayden MR: Cleavage at the caspase-6 site is required for neuronal dysfunction and degeneration due to mutant huntingtin. Cell 2006, 125(6):1179-1191.

15. Luo S, Vacher C, Davies JE, Rubinsztein DC: Cdk5 phosphorylation of huntingtin reduces its cleavage by caspases: implications for mutant huntingtin toxicity. J Cell Biol 2005, 169(4):647-656.

16. Schilling B, Gafni J, Torcassi C, Cong X, Row RH, Lafevre-Bernt MA, Cusack MP, Ratovitski T, Hirschhorn R, Ross CA, Gibson BW, Ellerby LM: Huntingtin phosphorylation sites mapped by mass spectrometry: Modulation of cleavage and toxicity. J Biol Chem 2006, 281:23686-23697.

17. Jeong H, Then F, Melia TJ Jr, Mazzulli JR, Cui L, Savas JN, Voisine C, Paganetti P, Tanese N, Hart AC, Yamamoto A, Krainc D: Acetylation targets mutant huntingtin to autophagosomes for degradation. Cell 2009, 137(1):60-72.

18. Yanai A, Huang K, Kang R, Singaraja RR, Arstikaitis P, Gan L, Orban PC, Mullard A, Cowan CM, Raymond LA, Drisdel RC, Green WN, Ravikumar B, Rubinsztein DC, El-Husseini A, Hayden MR: Palmitoylation of huntingtin by HIP14 is essential for its trafficking and function. Nat Neurosci 2006, 9(6):824-831.

19. Andrade MA, Bork P: HEAT repeats in the Huntington's disease protein. Nat Genet 1995, 11(2):115-116

20. Takano H, Gusella JF: The predominantly HEAT-like motif structure of huntingtin and its association and coincident nuclear entry with dorsal, an NF-kB/Rel/dorsal family transcription factor. BMC Neurosci 2002, 3(1):15.

21. Palidwor GA, Shcherbinin S, Huska MR, Rasko T, Stelzl U, Arumughan A Foulle R, Porras P, Sanchez-Pulido L, Wanker EE, Andrade-Navarro MA: Detection of alpha-rod protein repeats using a neural network and application to huntingtin. PLoS Comput Biol 2009, 5(3):e1000304.

22. Grinthal A, Adamovic I, Weiner B, Karplus M, Kleckner N: PR65, the HEATrepeat scaffold of phosphatase PP2A, is an elastic connector that links force and catalysis. Proc Natl Acad Sci USA 2010, 107(6):2467-2472.

23. Goehler H, Lalowski M, StelzI U, Waelter S, Stroedicke M, Worm U, Droege A, Lindenberg KS, Knoblich M, Haenig C, Herbst M, Suopanki J, Scherzinger E, Abraham C, Bauer B, Hasenbank R, Fritzsche A, Ludewig AH, Bussow K, Coleman SH, Gutekunst CA, Landwehrmeyer BG, Lehrach H, Wanker EE: A protein interaction network links GIT1, an enhancer of huntingtin aggregation, to Huntington's disease. Mol Cell 2004, 15(6):853-865.
24. Kaltenbach LS, Romero E, Becklin RR, Chettier R, Bell R, Phansalkar A, Strand A, Torcassi C, Savage J, Hurlburt A, Cha GH, Ukani L, Chepanoske CL, Zhen Y, Sahasrabudhe S, Olson J, Kurschner C, Ellerby LM, Peltier JM, Botas J, Hughes RE: Huntingtin interacting proteins are genetic modifiers of neurodegeneration. PLoS Genet 2007, 3(5):e82.

25. Mangiarini L, Sathasivam K, Seller M, Cozens B, Harper A, Hetherington C, Lawton M, Trottier Y, Lehrach H, Davies SW, Bates GP: Exon 1 of the HD gene with an expanded CAG repeat is sufficient to cause a progressive neurological phenotype in transgenic mice. Cell 1996, 87(3):493-506.

26. Peters MF, Ross CA: Preparation of human CDNas encoding expanded polyglutamine repeats. Neurosci Lett 1999, 275(2):129-132.

27. Gaietta G, Deerinck TJ, Adams SR, Bouwer J, Tour O, Laird DW, Sosinsky GE, Tsien RY, Ellisman MH: Multicolor and electron microscopic imaging of connexin trafficking. Science 2002, 296(5567):503-507.

28. Ju W, Morishita W, Tsui J, Gaietta G, Deerinck TJ, Adams SR, Garner CC, Tsien RY, Ellisman MH, Malenka RC: Activity-dependent regulation of dendritic synthesis and trafficking of AMPA receptors. Nat Neurosci 2004, 7(3):244-253.

29. Trottier Y, Devys D, Imbert G, Saudou F, An I, Lutz Y, Weber C, Agid Y, Hirsch EC, Mandel JL: Cellular localization of the Huntington's disease protein and discrimination of the normal and mutated form. Nat Genet 1995, 10(1):104-110

30. Cong SY, Pepers BA, Roos RA, Van Ommen GJ, Dorsman JC: Epitope mapping of monoclonal antibody $4 \mathrm{C} 8$ recognizing the protein huntingtin. Hybridoma (Larchmt) 2005, 24(5):231-235.

31. Trottier Y, Lutz Y, Stevanin G, Imbert G, Devys D, Cancel G, Saudou F, Weber C, David G, Tora L, et al:: Polyglutamine expansion as a pathological epitope in Huntington's disease and four dominant cerebellar ataxias. Nature 1995, 378(6555):403-406.

32. del Toro D, Canals JM, Gines S, Kojima M, Egea G, Alberch J: Mutant huntingtin impairs the post-Golgi trafficking of brain-derived neurotrophic factor but not its Val66Met polymorphism. J Neurosci 2006, 26(49):12748-12757.

33. Strehlow AN, Li JZ, Myers RM: Wild-type huntingtin participates in protein trafficking between the Golgi and the extracellular space. Hum Mol Genet 2007, 16(4):391-409.

34. Caviston JP, Ross JL, Antony SM, Tokito M, Holzbaur EL: Huntingtin facilitates dynein/dynactin-mediated vesicle transport. Proc Natl Acad Sci USA 2007, 104(24):10045-10050.

35. Corthesy-Theulaz I, Pauloin A, Pfeffer SR: Cytoplasmic dynein participates in the centrosomal localization of the Golgi complex. J Cell Biol 1992, 118(6):1333-1345

36. Echeverri CJ, Paschal BM, Vaughan KT, Vallee RB: Molecular characterization of the 50-kD subunit of dynactin reveals function for the complex in chromosome alignment and spindle organization during mitosis. J Cell Bio/ 1996, 132(4):617-633.

37. Thyberg J, Moskalewski S: Role of microtubules in the organization of the Golgi complex. Exp Cell Res 1999, 246(2):263-279.

38. Burkhardt JK, Echeverri CJ, Nilsson T, Vallee RB: Overexpression of the dynamitin (p50) subunit of the dynactin complex disrupts dyneindependent maintenance of membrane organelle distribution. J Cell Biol 1997, 139(2):469-484.

39. He Y, Francis F, Myers KA, Yu W, Black MM, Baas PW: Role of cytoplasmic dynein in the axonal transport of microtubules and neurofilaments. $J$ Cell Biol 2005, 168(5):697-703.

40. Levy JR, Sumner CJ, Caviston JP, Tokito MK, Ranganathan S, Ligon LA, Wallace KE, LaMonte BH, Harmison GG, Puls I, Fischbeck KH, Holzbaur EL: A motor neuron disease-associated mutation in p150Glued perturbs dynactin function and induces protein aggregation. J Cell Biol 2006, 172(5):733-745

41. Gomez M, Scales SJ, Kreis TE, Perez F: Membrane recruitment of coatomer and binding to dilysine signals are separate events. J Biol Chem 2000, 275(37):29162-29169.

42. Jasmin BJ, Cartaud J, Bornens M, Changeux JP: Golgi apparatus in chick skeletal muscle: changes in its distribution during end plate development and after denervation. Proc Nat I Acad Sci USA 1989, 86(18):7218-7222.

43. Cole NB, Sciaky N, Marotta A, Song J, Lippincott-Schwartz J: Golgi dispersal during microtubule disruption: regeneration of Golgi stacks at peripheral endoplasmic reticulum exit sites. Mol Biol Cell 1996, 7(4):631-650. 
44. Li XJ, Li SH, Sharp AH, Nucifora FC Jr, Schilling G, Lanahan A, Worley P, Snyder SH, Ross CA: A huntingtin-associated protein enriched in brain with implications for pathology. Nature 1995, 378(6555):398-402.

45. Engelender S, Sharp AH, Colomer V, Tokito MK, Lanahan A, Worley P, Holzbaur EL, Ross CA: Huntingtin-associated protein 1 (HAP1) interacts with the p150Glued subunit of dynactin. Hum Mol Genet 1997, 6(13):2205-2212.

46. Li SH, Gutekunst CA, Hersch SM, Li XJ: Interaction of huntingtinassociated protein with dynactin P150Glued. J Neurosci 1998, 18(4):1261-1269.

47. Bertaux F, Sharp AH, Ross CA, Lehrach H, Bates GP, Wanker E: HAP1huntingtin interactions do not contribute to the molecular pathology in Huntington's disease transgenic mice. FEBS Lett 1998, 426(2):229-232.

48. McGuire JR, Rong J, Li SH, Li XJ: Interaction of Huntingtin-associated protein-1 with kinesin light chain: implications in intracellular trafficking in neurons. J Biol Chem 2006, 281(6):3552-3559.

49. Dompierre JP, Godin JD, Charrin BC, Cordelieres FP, King SJ, Humbert S, Saudou F: Histone deacetylase 6 inhibition compensates for the transport deficit in Huntington's disease by increasing tubulin acetylation. J Neurosci 2007, 27(13):3571-3583.

50. Caviston JP, Holzbaur EL: Huntingtin as an essential integrator of intracellular vesicular trafficking. Trends Cell Biol 2009, 19(4):147-155

51. Wanker EE, Rovira C, Scherzinger E, Hasenbank R, Walter S, Tait D, Colicelli J, Lehrach H: HIP-I: a huntingtin interacting protein isolated by the yeast two-hybrid system. Hum Mol Genet 1997, 6(3):487-495.

52. Pal A, Severin F, Lommer B, Shevchenko A, Zerial M: Huntingtin-HAP40 complex is a novel Rab5 effector that regulates early endosome motility and is up-regulated in Huntington's disease. J Cell Bio/ 2006, 172(4):605-618

53. Hattula K, Peranen J: FIP-2, a coiled-coil protein, links huntingtin to Rab8 and modulates cellular morphogenesis. Curr Biol 2000, 24:1603-1606.

54. Li X, Standley C, Sapp E, Valencia A, Qin ZH, Kegel KB, Yoder J, ComerTierney LA, Esteves M, Chase K, Alexander J, Masso N, Sobin L, Bellve K, Tuft R, Lifshitz L, Fogarty K, Aronin N, DiFiglia M: Mutant huntingtin impairs vesicle formation from recycling endosomes by interfering with Rab11 activity. Mol Cell Biol 2009, 29(22):6106-6116

55. Faber PW, Barnes GT, Srinidhi J, Chen J, Gusella JF, MacDonald ME: Huntingtin interacts with a family of WW domain proteins. Hum Mol Genet 1998, 7(9):1463-1474.

56. Haubensak W, Narz F, Heumann R, Lessmann V: BDNF-GFP containing secretory granules are localized in the vicinity of synaptic junctions of cultured cortical neurons. J Cell Sci 1998, 111:1483-1493.

57. Trettel F, Rigamonti D, Hilditch-Maguire P, Wheeler VC, Sharp AH, Persichetti F, Cattaneo E, MacDonald ME: Dominant phenotypes produced by the HD mutation in STHdh(Q111) striatal cells. Hum Mol Genet 2000, 9(19):2799-2809.

58. Saudou F, Finkbeiner S, Devys D, Greenberg ME: Huntingtin acts in the nucleus to induce apoptosis but death does not correlate with the formation of intranuclear inclusions. Cell 1998, 95:55-66.

59. Crespo PM, Silvestre DC, Gil GA, Maccioni HJ, Daniotti JL, Caputto BL: C-Fos activates glucosylceramide synthase and glycolipid synthesis in PC12 cells. J Biol Chem 2008, 283(45):31163-31171.

60. Bolte S, Cordelieres FP: A guided tour into subcellular colocalization analysis in light microscopy. J Microsc 2006, 224(Pt 3):213-232.

Submit your next manuscript to BioMed Central and take full advantage of:

- Convenient online submission

- Thorough peer review

- No space constraints or color figure charges

- Immediate publication on acceptance

- Inclusion in PubMed, CAS, Scopus and Google Scholar

- Research which is freely available for redistribution

Submit your manuscript at www.biomedcentral.com/submit
C Biomed Central 